\title{
Evolution Characteristics of ERP Systems that Distinct from Traditional SDLCs
}

\author{
Basem Zughoul ${ }^{1}$, Mohammed Al-Refai ${ }^{2}$, Nidhal El-Omari ${ }^{3}$ \\ Department of Software Engineering, Faculty of IT, Aqaba University of Technology, Aqaba, Jordan ${ }^{1}$ \\ Department of Software Engineering, Faculty of IT, Zarqa University, Zarqa, Jordan ${ }^{2}$ \\ Department of Software Engineering, Faculty of IT, WISE University, Amman, Jordan ${ }^{3}$
}

\begin{abstract}
Information systems designed and developed in house to fit a specific or small set of functions. It's typically much smaller than enterprise system, however most of these developments also required more time, high cost to develop, not integrated, unclear customer requirements, and the most importantly working version is available during the implementation phase. On the other hand, many organizations rely on Enterprise Resource Planning (ERP) systems to manage and process their entire business requirements, including a large size of applications, where these systems comply with various business needs, like expanding markets, increasing competition and technology developments. Most of ERP systems should have specific characteristics to achieve the developments of business processes. ERP systems work in dealing with customization off-the-shelf ERP package, or changing organization business process and people structure to suite with the package. This constitutes a handicap for both the research and practice communities. The present study outlines the main and specific characteristics distinct from other information systems and discusses the influence of various enterprise system characteristics such as standardization integration, flexibility, best practices and process-orientation. The aim of this study is to recapitulation of the main characteristics of ERP systems and concludes the impact of ERP key characteristics upon the performance of the system in a given organizational setting and focusing on functionality, procedures and business needs in organizations.
\end{abstract}

Keywords: Information System, Enterprise Resource Planning, Integration, Enterprise System, Software Packages.

\section{INTRODUCTION}

Today, public and private organizations are facing systems that will streamline and standardize business different challenges while running their business. These processes and deliver tighter control and flexibility of challenges include expanding markets, increasing operations [3].

competition, rising customer expectations, increasing needs for technology; and many others. Thus, there is a need for information system to manage all these aspects [1].

Information Systems (IS) are an arrangement of several components such as hardware, software, communications systems, people, process, and data. Therefore, most organizations use information systems to interact and improve their day-to-day business activities and operations, to support the problem solving and help decision making. Hence, they become critical components for any successful organizations. Information systems provide a high level of computers automation to carry out different business functions like finance, accounting, marketing, human resources management, customer services and operations [2].

Many companies regard and rely on ERP systems to manage and process their business according to the benefits of ERP systems, although of the high cost associated to enterprise software. To launch an ERP system a company would need to invest in hardware, software and maintenance. Another fundamental cost driver is the need for adaptation of standard software [4].

As more and more organizations move from functional to process-based IT infrastructure, ERP systems are becoming one of today's most widespread IT solutions [5].

Enterprise Resource Planning system is also known as an integrative information system that supports the work processes and resource management of an organization [6].

Enterprise systems or enterprise resource planning (ERP) The development of information systems contained systems are considered one of the most important business several applications, large size, high cost, large innovations and expected to have a significant impact on several aspects organizations. These enterprise systems have promised to replace discrete, un-integrated information systems with integrated enterprise wide development teams, and usually required limit time schedule [7]. The implementation process of these systems associated massive change in organization structure, business process, and people work [8]. 


\section{IJARCCE}

Nowadays, the world is facing another revolution biggest increasing competition, business requirements, and rising and most complex after industrial revolution, which is the customer expectations. This increases the pressure to information technology revolution. The increase of the reduce total costs with less time [1]

popularity of internet, WWW, new technological According the literatures, there are many organizations development in mobile computing and artificial which have adopted these ERP systems into their business intelligence is changing the business requirements and systems management to minimize the cost and save time business practices. In addition, regarding to inflexibility, through cutting the amount of paperwork, labor cost for the execution of this type of software according to the operating and maintenance [14], [15]. ERP system uses a business requirements, needs a high costly, time and commonly shared database management system in order to efforts. Also there are important problems that face these provide access to the information to and/from all systems: the compatibility with developments of hardware departments within an organization at the same time. This and software, integration and redundancy of data between enables decisions to be made from an enterprise point of these modules [9].

ERP system are customizable, standard application software that includes integrated business solutions, providing a significant improvements in efficiency, productivity and service quality, and reduce in service costs as well as to more effective decision-making [10].

\section{ERP SYSTEMS}

ERP system solutions are currently in high demand by both manufacturing and service organizations because they provide a tightly integrated solution to an organization's information system needs [11]. ERP systems have been known as systems that bring integration to several business activities within complex organizations, ERP systems are becoming a standard information system, irrespective of the size and nature of the organization, so the drives for ERP systems are technological and operational factors [12]:

- Technological factor is replacement of disparate systems (hardware/software) because of difficulty of maintenance, integration of processes and systems, and the software does not meet business needs.

- Operational factors are customer satisfaction, improvement of process, simplification of complex process, and standardization of process.

ERP system has the ability to automate and integrate the business processes of organization, to share common data and practices across the organization, and to produce and access information in real time [13].

\section{ADOPTION OF ERP SYSTEMS}

The business environment is significantly changing. Companies today face the challenge of expanding markets, view, rather than making a decision from a separate department, and then coordinating the information manually. In addition, there are a lot of reasons for buying and using ERP system, the major reason according to [16] that ERP system uses a common shared database management system enables easier access to information by all departments within an organization in same time.

Although moving from client-server architecture to internet architecture, or by changes in the business environment, so vendors are constantly evolving to meet the changing business demands, and allow the organization to move agilely and adapt quickly changes in the business environment [17],[18].

[19] Presented four reasons that urge organizations to implement ERP system: (1) simplify and standardize systems, (2) replace legacy systems, (3) gain strategic advantage, (4) improve interaction between suppliers and customers.

ERP Packages fit organizations needs of all sizes, ERP market was $\$ 16.67$ billion in 2005 and forecasted to be over \$21 billion in 2010 [20]. Also according to [21] ERP is large information system, many organization have to adopt ERP systems, and there are over 35 hundred million U.S. dollar has been invested in the deployment of ERP, and over 60,000 companies have already implemented ERP system in the whole world.

ERP system implementation can bring significant benefits, such as manage and integrate business processes across various functions, minimize sharing time for information, streamline the business processes and enhance the competitive advantage [22]. A summary of the past studies about the reasons and significance for organizations to adopt ERP system implementation is classified into technical and business reasons. However, it is important to take into account these wide variations in motivation to adopt enterprise systems as shown in Table I.

\section{TABLE I SUMMARY OF MAJOR ADVANTAGES AND BENIFITS OF ORGANIZATIONS ADOPTED ERP} SYSTEM

\begin{tabular}{|c|c|c|c|c|c|c|c|c|c|c|c|c|c|c|c|}
\hline $\begin{array}{c}\text { Technical and Business } \\
\text { Advantages }\end{array}$ & $\underset{\omega}{\tilde{\omega}}$ & $\stackrel{N}{ \pm}$ & $\vec{a}$ & $\underset{N}{\tilde{N}}$ & $\widetilde{\sigma}$ & 正 & $\bar{\Omega}$ & 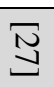 & $\underset{\infty}{\mathbb{N}}$ & $\sqrt{\sigma}$ & $\bar{\omega}$ & $\underline{N}$ & $\underline{\omega}$ & $\stackrel{N}{N}$ & $\bar{\omega}$ \\
\hline Integration & & & $\sqrt{ }$ & $\sqrt{ }$ & & $\sqrt{ }$ & $\sqrt{ }$ & $\sqrt{ }$ & $\sqrt{ }$ & $\sqrt{ }$ & & $\sqrt{ }$ & $\sqrt{ }$ & $\sqrt{ }$ & $\sqrt{ }$ \\
\hline Productivity and quality & & $\sqrt{ }$ & $\sqrt{ }$ & $\sqrt{ }$ & & & & & & $\sqrt{ }$ & & & $\sqrt{ }$ & & $\sqrt{ }$ \\
\hline Standardization & & $\sqrt{ }$ & & $\sqrt{ }$ & $\sqrt{ }$ & $\sqrt{ }$ & & & & & $\sqrt{ }$ & & & & $\sqrt{ }$ \\
\hline
\end{tabular}


International Journal of Advanced Research in Computer and Communication Engineering ISO 3297:2007 Certified

Vol. 5, Issue 7, July 2016

\begin{tabular}{|c|c|c|c|c|c|c|c|c|c|c|c|c|c|c|c|}
\hline Improve Business Process & & $\sqrt{ }$ & & $\sqrt{ }$ & & $\sqrt{ }$ & & $\sqrt{ }$ & $\sqrt{ }$ & & & $\sqrt{ }$ & $\sqrt{ }$ & & $\sqrt{ }$ \\
\hline Business Strategic Advantage & & & & & $\sqrt{ }$ & $\sqrt{ }$ & & & & $\sqrt{ }$ & & $\sqrt{ }$ & & $\sqrt{ }$ & \\
\hline Business Profit \& Cost Reduction & & $\sqrt{ }$ & & $\sqrt{ }$ & & & & $\sqrt{ }$ & $\sqrt{ }$ & $\sqrt{ }$ & & & $\sqrt{ }$ & $\sqrt{ }$ & $\sqrt{ }$ \\
\hline Improve Decision Making & & & $\sqrt{ }$ & $\sqrt{ }$ & & $\sqrt{ }$ & & & $\sqrt{ }$ & $\sqrt{ }$ & $\sqrt{ }$ & $\sqrt{ }$ & & $\sqrt{ }$ & \\
\hline Respond to Change Environment & $\sqrt{ }$ & $\sqrt{ }$ & & & & & & $\sqrt{ }$ & $\sqrt{ }$ & & $\sqrt{ }$ & & & $\sqrt{ }$ & $\sqrt{ }$ \\
\hline Replace Legacy System & $\sqrt{ }$ & & & $\sqrt{ }$ & $\sqrt{ }$ & & & & & $\sqrt{ }$ & & $\sqrt{ }$ & & & \\
\hline Market Share & & $\sqrt{ }$ & & $\sqrt{ }$ & & & & & $\sqrt{ }$ & & & & $\sqrt{ }$ & & \\
\hline Real Time Processing & & $\sqrt{ }$ & $\sqrt{ }$ & & & & $\sqrt{ }$ & & & $\sqrt{ }$ & $\sqrt{ }$ & $\sqrt{ }$ & $\sqrt{ }$ & & $\sqrt{ }$ \\
\hline Improve Delivery Time & $\sqrt{ }$ & $\sqrt{ }$ & $\sqrt{ }$ & & & & & & $\sqrt{ }$ & $\sqrt{ }$ & & $\sqrt{ }$ & $\sqrt{ }$ & $\sqrt{ }$ & \\
\hline Interact suppliers and customers & $\sqrt{ }$ & $\sqrt{ }$ & & & $\sqrt{ }$ & & $\sqrt{ }$ & & $\sqrt{ }$ & $\sqrt{ }$ & $\sqrt{ }$ & $\sqrt{ }$ & & & $\sqrt{ }$ \\
\hline
\end{tabular}

\section{CHARACTERISTICS OF ERP SYSTEMS}

ERP system has a set of specific characteristics, so these characteristics is derived and based on the literature search on ERP system characteristics in general and the comparisons with traditional IT project.

Therefore, in this work the unique features of ERP project were identified and used as a help to understand what they are, what they can do, how they differ from other IT packages, and what characteristics of an ERP development methodology [23].

For a better understanding, the ERP characteristics regrouped under three dimensions according to their classifications, namely technical, organizational and informational as described below [10]:

- Technical dimension includes flexibility, complexity and openness; it refers to the capabilities for applications development offered by ERP systems in comparison to traditional systems.

- Organizational dimension includes integration, best practices, completeness and change process; it refers to the

This paper identifies the main characteristics of ERP systems such as complexity, integrated and packaged software, which perform number of applications through a number of functions, and manage the organization with the integration of business processes [32]. system's deployment in the firm that is the best reflect impact of system on organization.

- Informational dimension includes software package relates to the quality and usefulness of the information provided by the system as presented below (see Fig. 1).

Dimension

Characteristcs

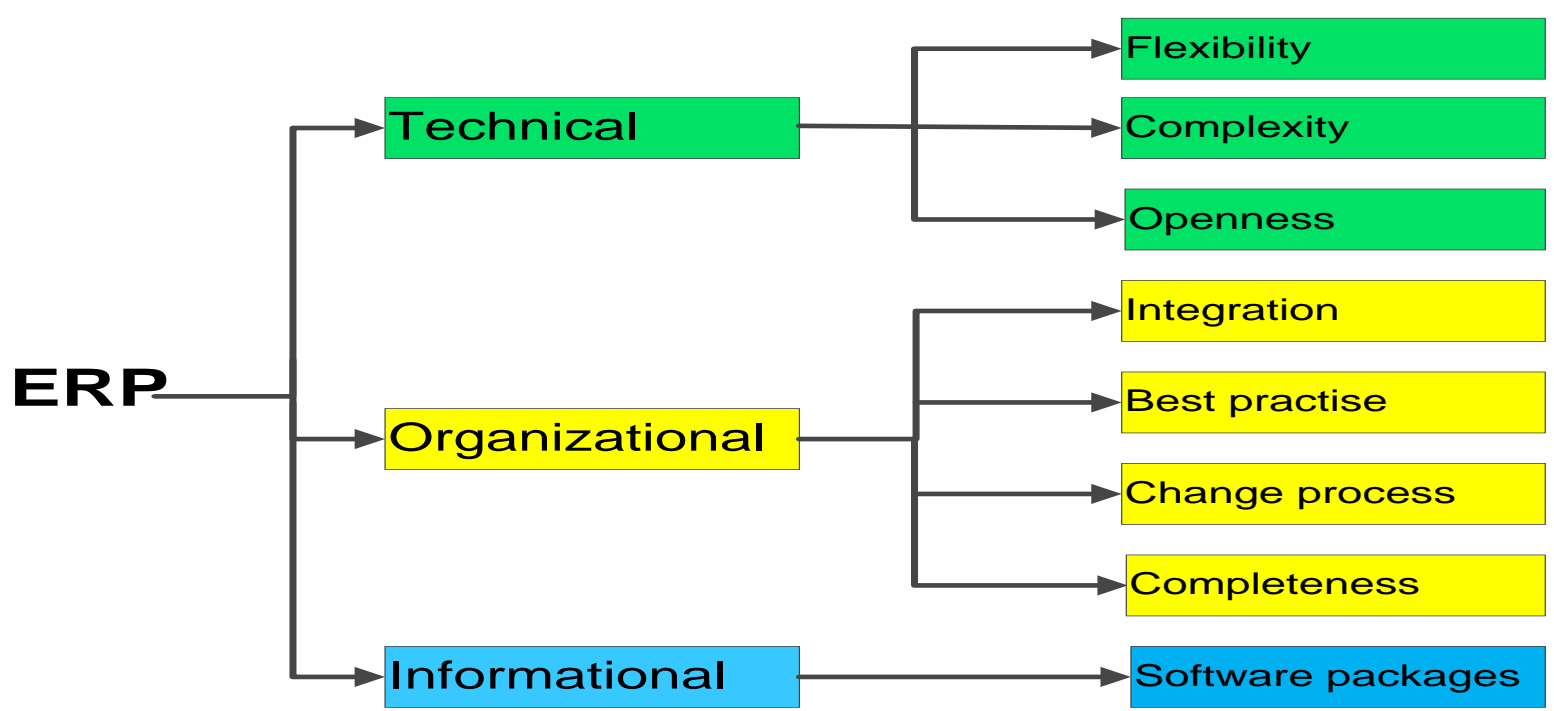

Fig. 1. ERP Characteristics regrouped under three dimensions

\section{DISCUSSION OF ERP SYSTEM CHARACTERISTICS}

This study identifies the main characteristics of ERP Flexibility: it is one of the specialist characteristics that systems such as complexity, integrated and packaged are differentiation ERP system from other IT project [24]. software, which perform number of applications through a This characteristic is particularly important to the strategic 
business decision. Therefore organizations perform customization and configuration ERP system in order to achieve object ivies and reach to competitive advantages [1], [6], [19].

Complexity: ERP system is the most complex software within the most information system. It usually includes one application, which can be operated separately of other organizational applications with friendly user interface [6], [8], [23], [33], [34].

Software Packages: it is one of the essential characteristics that are distinguishes ERP system from custom built software, because it is developed to meet the general needs of a group of organizations. ERP software packages must be designed in a way that organizations can be customized, in order to add/remove or reconfigure these modules to respond to the specific organization needs [23], [24], [35].

Integration: Integration is defined as the coordination of activities, processes and exchanges of the information across units or departments and functions, this property is representing an extremely important part and provides a tightly integrated solution to ERP system, and it's one of the core functions that differ from previous IT project. [23], [33].

Best Practices: ERP system is implement the best business practices to serves a large variety of organization. It adopted many options to fit and support various business processes used in different type of organization. This characteristic represents a powerful reason to adopt an ERP system without modifying the process of business [33], [36], [38].

Completeness: Complexity defined that the system consists of many components, many interactions and relationships, and deals with a variety of hardware, software and human components. ERP is much broader scope than that early software packages; they designed to affect the entire enterprise structure rather than unique or set of function those traditional software packages [6], [23].

Openness: ERP system has evolving over several years and most organizations need to implement ERP system to replacement or upgrading the existing infrastructure. It was gradual and continuous developments without considerable changes, these characteristics allow ERP system flexibility to the organization [1], [6], [37].

Change Process: ERP project can be viewed as an organizational change due to the large number of changes it brings to an organization structure like workflow processes, business process and the way people do job. ERP system makes different impacts on most aspects of the environment of the organization like technology, task, structure, people, culture, strategy and size [1], [17], [13], [27].

\section{CONCLUSION}

Enterprise Resource Planning system is designed to implement an entire business solution which supports major business functionalities of an enterprise. The ability of enterprise systems (ES) to integrate processes and information and to deliver automation and consistent execution of processes across the enterprise is important to all type of organizations. Carefully comparing the challenges and potential benefits, increasing availability of cost-effective of ES in the marketplace. Successful adoption, implementation and exploitation of enterprise systems is dependent on factors such as suitable to fit between ES solution and their processes, and the extent of standardization and integration of information and processes achieved after implementation. The services and service oriented architecture and their incorporation into the enterprise systems software solutions is expected to make it possible to build bridges between disparate IT systems across and between the enterprises.

\section{REFERENCES}

[1] Iskanius, Päivi. "Risk Management in ERP Project in the Context of SMEs." Iskanius, Päivi 17, no. 4 (2009).

[2] Jigeesh, N. "Study on Factors Influencing Selection and Implementation of ERP Systems." Asian Journal of Information Technology, (2011) : 65-77.

[3] Seethamraju, R. and Sundar, D." Influence of ERP systems on business process agility." IIMB Management Review, vol. 25, no. 3, (2013): 137-149.

[4] Borovskiy, Vadym, and Alexender Zeier. "Enabling Enterprise Composite Application on Top of ERP Systems." IEEE Services Computing Conference. 2009. 492-497.

[5] Motwani, J., R. Subramanian, and P. Gopalakrishna. "Critical factors for successful ERP implementation: Exploratory findings from four case studies." Computers in Industry 56, no. 6 (2005): 529-544.

[6] Ahituv, Niv, Seev Neumann, and Moshe Sviran. "A System Development Methodology for ERP Systems." Computer Information Systems, 2002: 56-67.

[7] Umble, Elisabet J., Ronald R. Haft, and M. Michael Umble. "Enterprise resource planning: Implementation procedures and critical success factors." European Journal of Operational Research 146, no. 2 (2003): 241-257.

[8] Appuswamy, R. "Implementation iss in ERP." International Conference on System Thinking in Managment. 2000. 1-8.

[9] Fang, A.-r., Li, Y.-j., Lu, Q., Sun, B.-n. and Ye, Q. "The process of ERP usage in manufacturing firms in China: An empirical investigation." International Conference on Management Science and Engineering, (2009): 3-9.

[10] Zughoul, Basem and Hussin, Burairah "Factors Effecting Migration Traditional Projects to Enterprise Resource Planning System (ERP)", International Review on Computers \& Software(IRECOS), Vol. 8, Issue 8, pp. 2005-2012, Aug 2013.

[11] Shehab, E. M., M. W. Sharp, and T. A. Spedding. "Enterprise resource planning An integrative review." Business Process Management Journal 10, no. 4 (2004): pp. 359-386.

[12] Okunoye, Adekunle, Frolick Mark, and Crable Elaine. "ERP Implementation in Higher Education: An Account of PreImplementation and Implementation Phases." Cases on information technology 8 , no. 3 (2006): 110-133.

[13] Nah, Fiona Fui-hoon, Janet Lee-shang Lau, and Jinghua Kuang. "Critical factors for successful implementation of enterprise systems." Business Process Management Journal 7, no. 3 (2001): 285-296.

[14] He, Y. "A Comparative Study of Critical Success Factors for ERP System Implementation in China and Finland", (2007). 
[15] Elragal, A.; Haddara, M. "The Future of ERP Systems: look backward before moving forward". International Conference on Health and Social Care Information Systems and Technologies, vol. 5, no. 2212, (2012): 21-30.

[16] Spaith, C., and S. Constantinides. "The usefulness of ERP systems for effective management." Industrial Management \& Data System, 2003: 677-685.

[17] Yusuf, Yahaya. "Enterprise information systems project implementation: A case study of ERP in Rolls-Royce." International Journal of Production Economics 87, no. 3 (2004): 251-266.

[18] Kapp, K., F. William, and N. Hester. Integrated learning for ERP success: a learning requirements planning approach. New York: Amazon, 2001

[19] Sumner, Mary. Enterprise Resource Planning. Prentice Hall, 2005.

[20] Leon, Alexis. "ERP Demystified second edition-study guide." In ERP Demystified(Second Edition), by Alexis Leon. Singapore: McGraw-Hill, 2008.

[21] Chen, C.-C., Shih, D.-H., Chiang, H.-S., \& Lai, C.-Y. The "Affecting on the Performance of Introducing Different ERP Strategies." International Review on Computers and Software(IRECOS). (2011). 6. n.5, 765-773.

[22] Choi, T., Chow, P. and Liu, S. "Implementation of fashion ERP systems in China: Case study of a fashion brand, review and future challenges." International Journal of Production Economics, (2012): 1-12.

[23] Brehm, L. "Tailoring ERP Systems : A Spectrum of Choices and their Implications." Proceedings of the 34th Hawai'i International Conference on System Sciences. 2001

[24] Rashid, Mohammad, and Liaquat Hossain. "The Evolution of ERP Systems : A Historical Perspective." Idea Group Publishing, 2002

[25] Holsapple, C. "ERP plans and decision-support benefits." Decision Support Systems, (2005): 575-590.

[27] Sawah, Sondoss, Assem Tharwat, and Mohamed Rasmy. "A quantitative model to predict the Egyptian ERP implementation success index." Business Process Management Journal 14, no. 8 (2008): 288-306.

[28] Peslak, R., Subramanian, G. and Clayton, G. "The Phases of ERP Software Implementation and Maintenance : a model for predicting preferred ERP use." Information Systems, vol. 48, (2008): 25-33.

[28] Tsai, W., Y. Shen, P. Lee, and L. Kuo. "An empirical investigation of the impacts of ERP consultant selections and project management on ERP is success assessment." 2009 IEEE International Conference on Industrial Engineering and Engineering Management. 2009. 568-572.

[29] Ibrahim, A.M.S. "What Organaisation Should Know About Enterprise Resource Planning ( ERP ) System." European, Mediterranean \& Middle Eastern Conference on Information Systems (2010): 1-16

[30] Gorla, N., Somers, T.M. and Wong, B. "Organizational impact of system quality, information quality, and service quality." The Journal of Strategic Information Systems, (2010): 207-228.

[31] Supramaniam, M., Kuppusamy, M. "Analysis of Critical Success Factors in Implementation Enterprize Resource Planning Ssystems in Malaysia Business Firms." The Electronic Journal on Information Systems in Developing Countries (2011): 1-19.

[32] Leon, A. "ERP Demystified second edition-study guide." Singapore: McGraw-Hill (2008).

[33] Negi, T., and Veena Bansal. "A Metric for ERP Complexity." Business Information Systems, 2008.

[34] Lind, Mikael, and Jonas Hedman. Is there only one systems development life cycle? Springer-Verlag US, 2009.

35] Hoffer, A. Jeffery. Modern System Analysis and Design (Sixth Edition ed). Upper Saddle River, New Jersey 07458: Pearson Education, Inc, 2011.

[36] Ioannoua, G., and C. Papadoyiannisab. "Theory of ConstraintBased Methodology for Effective ERP Implementation." International Journal of Production Research 42, no. 23 (2004): 4927-4954.

[37] Mulazzani, F., B. Russo, and G. Succi. "ERP Systems Development: Enhancing Organization's Strategic Control through Monitoring Agents." Eigth IEEE/ACIS International Conference on Computer and Information Science. Bolzano, Italy, 2009. 535-542.
[38] Soffer, P, B Golany, and D Dori. "Aligning an ERP system with enterprise requirements: An object-process based approach." Computers in Industry 56, no. 6 (2005): 639-662.

\section{BIOGRAPHY}

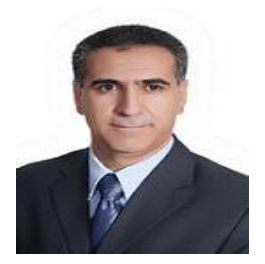

Basem Zughoul Ph.D. in Software and Information Systems Engineering from University Technical Malaysia Melaka in 2014. He received his M.Sc. in Computer Information Systems from University of Banking and Financial Sciences in 2006. $\mathrm{He}$ received his B.Sc. in Computer Science from Yarmouk University in 1985. He is currently Assistant Prof. at the software engineering department in IT faculty in Aqaba University of Technology in Jordan. His main research of interest is in ERP systems, software process models.

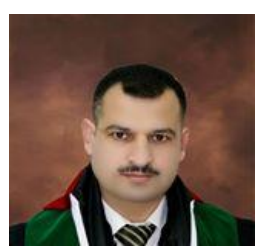

Mohammed Al-Refai Ph. D. in Computer Science (CS) from Amman Arab University for Graduated studies, Jordan 2/2007. He received his M.Sc. in Computer Science from Alalbayet University, Jordan 3/2002. He received his B.Sc. in Computer Science from Mutah University, Jordan 6/1992. He is currently the chairman of software engineering department in IT faculty in Zarqa University in Jordan. His main research interests include many aspects in parallel and distributed systems, simulation and project management.

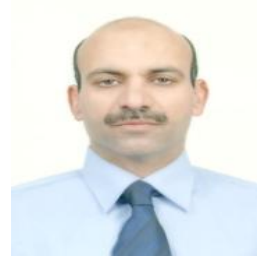

Nidhal El-Omari Ph. D. in Computer Information System (CIS) from Arab Academy for Banking and Financial Sciences, Jordan 2008. He obtained the B.Sc. in Computer Science and M.Eng. degree in Computer Engineering in 1986 and 2005, respectively, both from Yarmouk University, Jordan. He is currently in the chairman of software engineering department in IT faculty in WISE University in Jordan. His main research interests include: Image Compression \& Segmentation, Artificial Neural Network (ANN), Artificial Bees Colony System (ABC), Wireless Networks, and Programming Languages and Methodologies for building correct, secure and efficient software. 